\title{
An Evaluation of Pneumatic Orthoses in Thoracic Paraplegia
}

\author{
R. K. Strachan, F.R.C.S.; ${ }^{1}$ J. Cook, F.R.C.S.; ${ }^{2}$ W. Wilkie, M.C.S.P.; ${ }^{3}$ and \\ N. S. J. Kennedy, Ph.D. ${ }^{4}$ \\ ${ }^{1}$ Department of Orthopaedics, Royal Infirmary of Edinburgh, Lauriston Place, \\ Edinburgh. ${ }^{2}$ Eastern General Hospital, Edinburgh. ${ }^{3}$ Spinal Unit, Edenhall \\ Hospital, Musselburgh. ${ }^{4}$ Department of Medical Physics, Ninewells Hospital, \\ Dundee, U.K.
}

\begin{abstract}
Summary
Pneumatic orthoses were used to mobilise eight post-traumatic thoracic paraplegic males whose progress was monitored for two years. The pneumatic orthosis was more likely to be used than pelvic brace and calipers mainly due to increased support for the pelvis and the thoracolumbar spine. The effects of the orthosis and the mobilisation upon patient physiology were studied. Beneficial effects upon cardiovascular and respiratory systems were noted and increases in total body calcium after mobilisation were found. Contraindications to fitting the orthosis include severe spasms, obesity and scoliosis.
\end{abstract}

Key words: Thoracic paraplegia; Pneumatic orthoses; Mobilisation; Physiological assessment; Total body calcium.

\section{Introduction}

Pneumatic suits were originally designed to meet the needs of the aerospace industry and Morel (1971) conceived their use as orthoses to provide support and protection in osteogenesis imperfecta. Commercial production started in France soon after and also in Wales.

This orthosis was chosen for study because it can provide support for paraplegics with lesions above the lower thoracic segments who had either discarded or had not been thought suitable for fitting with pelvic brace and calipers (Fig. 1). The orthosis is made of a lightweight nylon webbing which embraces trunk and lower limbs from the scapulae to the malleoli with tension being adjusted by a combination of laces and straps and with support at the ankle being provided by toe and plantar straps. At the front and back on both sides, inflatable tubes run the length of the suit which are inflated by a portable compressor in two or three minutes to a pressure of $1.8 \mathrm{Kg} / \mathrm{cm}^{2}$. These give support and a degree of spring during the swing-through gait using forearm crutches. Once the suit is adjusted to the individual, dressing only involves zip fasteners and deflation is controlled by a hand held valve at the front of the suit. 


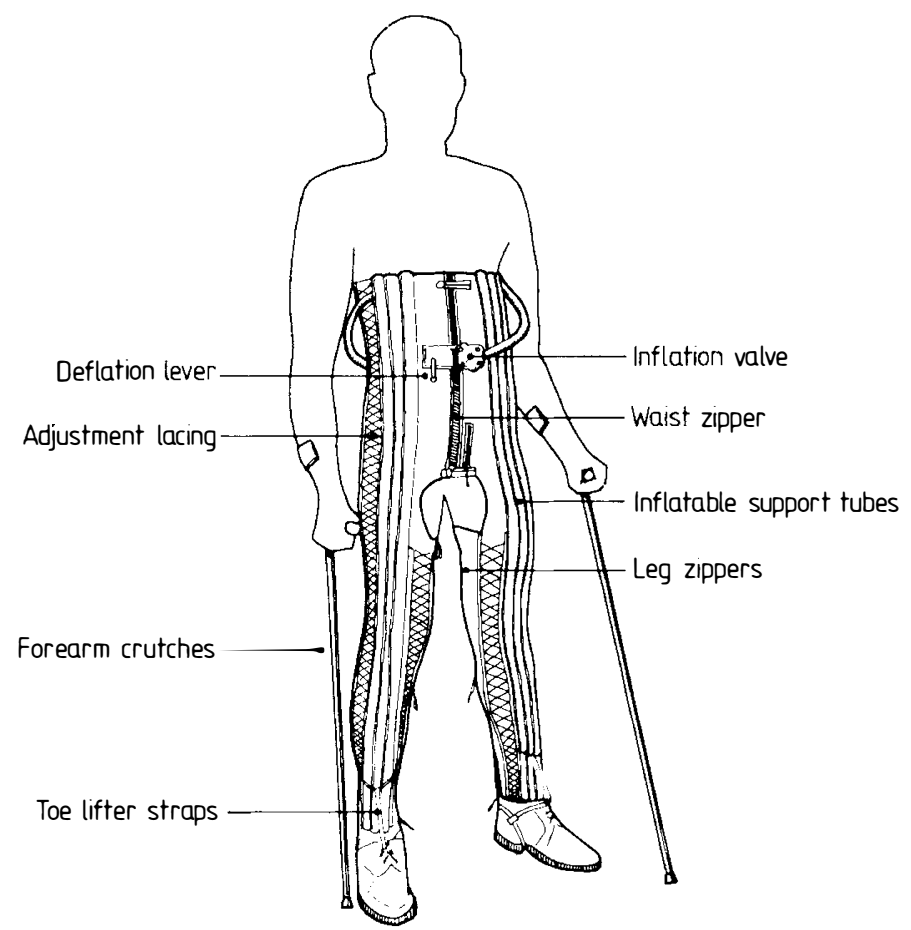

Figure 1. Diagram of a Pneumatic Orthosis.

Compressed air cylinders are also available. Long underpants protect the skin and urine is collected in a leg-bag outside the suit.

\section{Methods}

Initial experience in fitting the orthosis was gained during the mobilisation of one thoracic paraplegic and one low cervical tetraplegic with good shoulder musculature and grip. A further eight males with post-traumatic paraplegia, ranging in age from 20 to 45 years, with complete lesions of the spinal cord at or above the 9 th thoracic segment were then trained.

A standard set of achievement goals, Table 1, was used to assess the progress each day and a record made of the times for fitting the suit, length of inflation and duration of mobilisation as well as any problems or untoward symptoms encountered. The orthoses were fitted from 6 months to 15 years after injury with the late fittings at 1, 2, 5 and 15 years all being for patients who had failed with calipers. A questionnaire was then used to determine utilisation rates and subsequent problems.

After successful fitting of the orthosis, a tiling table was used in combination with serial pulse measurements, sphygmomanometry and respirometry to obtain mean values in response to assuming an erect posture before inflation and then after inflation, leaving at least 5 minutes between estimations. Prior to entry into the trial and once again at 6 months after entry, haematological and plasma 


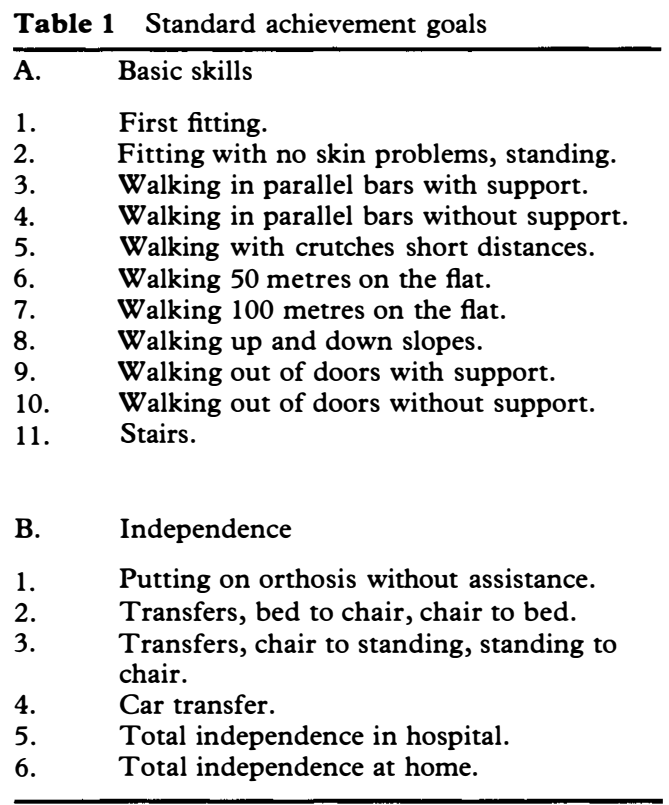

and urinary biochemical estimations were performed including haemoglobin, white cell count and mean corpuscular volume, plasma calcium, phosphate, alkaline phosphatase, urea, creatinine and parathormone and urinary calcium, phosphate, creatinine, hydroxyproline, creatinine clearance and therefore hydroxyproline/creatinine ratios. At the same times as the plasma and urinary estimations were being carried out, changes in total body calcium were measured using total body in-vivo neutron activation analysis. The patients stood with their suit inflated in a polythene irradiation kiosk, Kennedy et al., (1982). Following irradiation by a cyclotron the patient was transferred to a whole body counter where the induced Calcium 49 was measured for twenty minutes. Computer analysis of the induced radiation spectrum gave a result in grammes of calcium. The measured value was corrected for height and weight by expressing it as a percentage of the predicted normal total body calcium which had been obtained from normal volunteers. The precision or reproducibility of the technique was $1.8 \%$ based on long term measurements of an anthropomorphic phantom.

\section{Results}

\section{Mobilisation and utilisation}

Table 2 gives the individual patient data and the eventual outcome. Category A includes those patients not previously mobilised in calipers and Category B includes those that had. The time required for fitting averaged $7 \cdot 3$ hours $(2 \cdot 5-13$ range). There were a few specific problems, mainly adjustments of toe straps, knee pads and the clip on the dorsum of the foot. The skin over the patella quite often became erythematous after prolonged mobilisation but this did not lead to complications after knee pads had been adjusted. The patient with a 


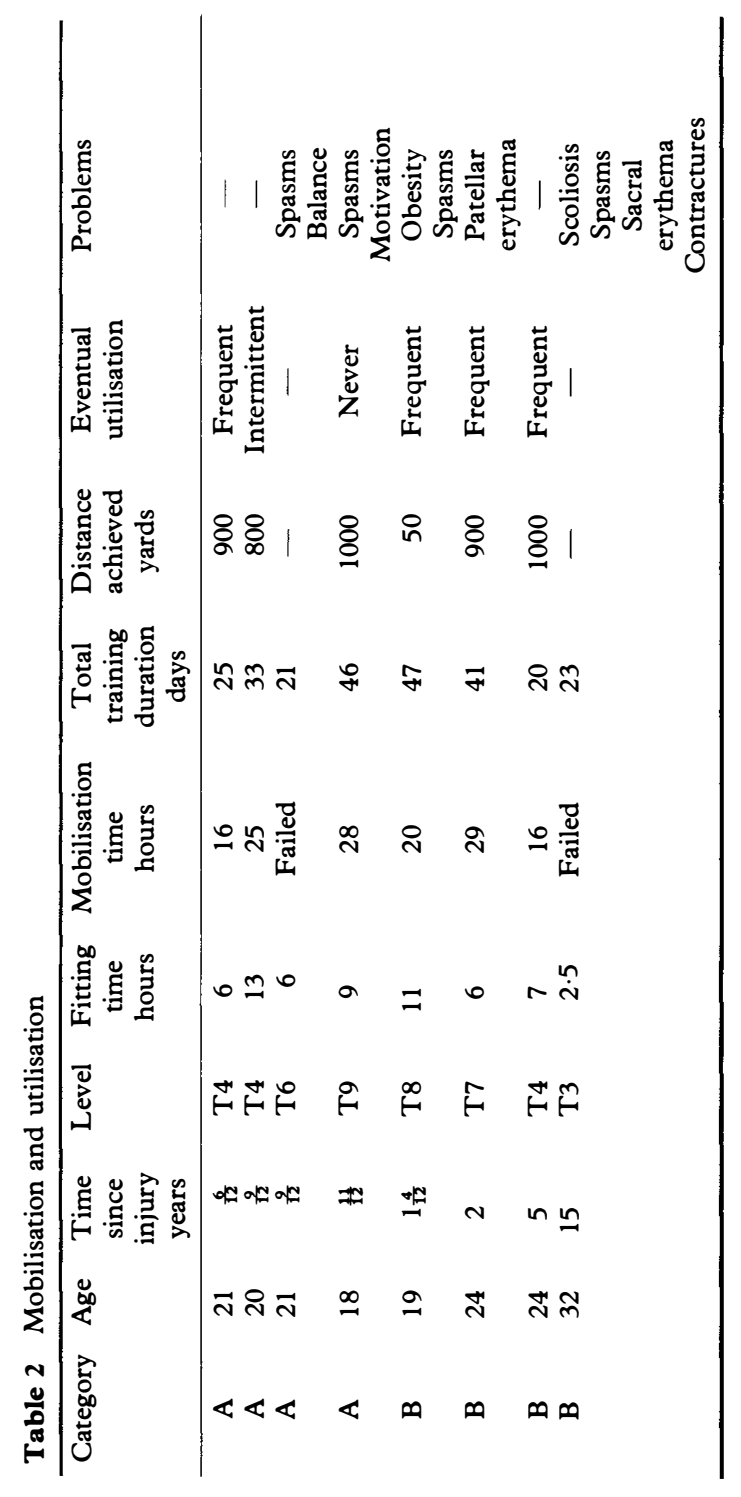


PNEUMATIC ORTHOSES IN THORACIC PARAPLEGIA

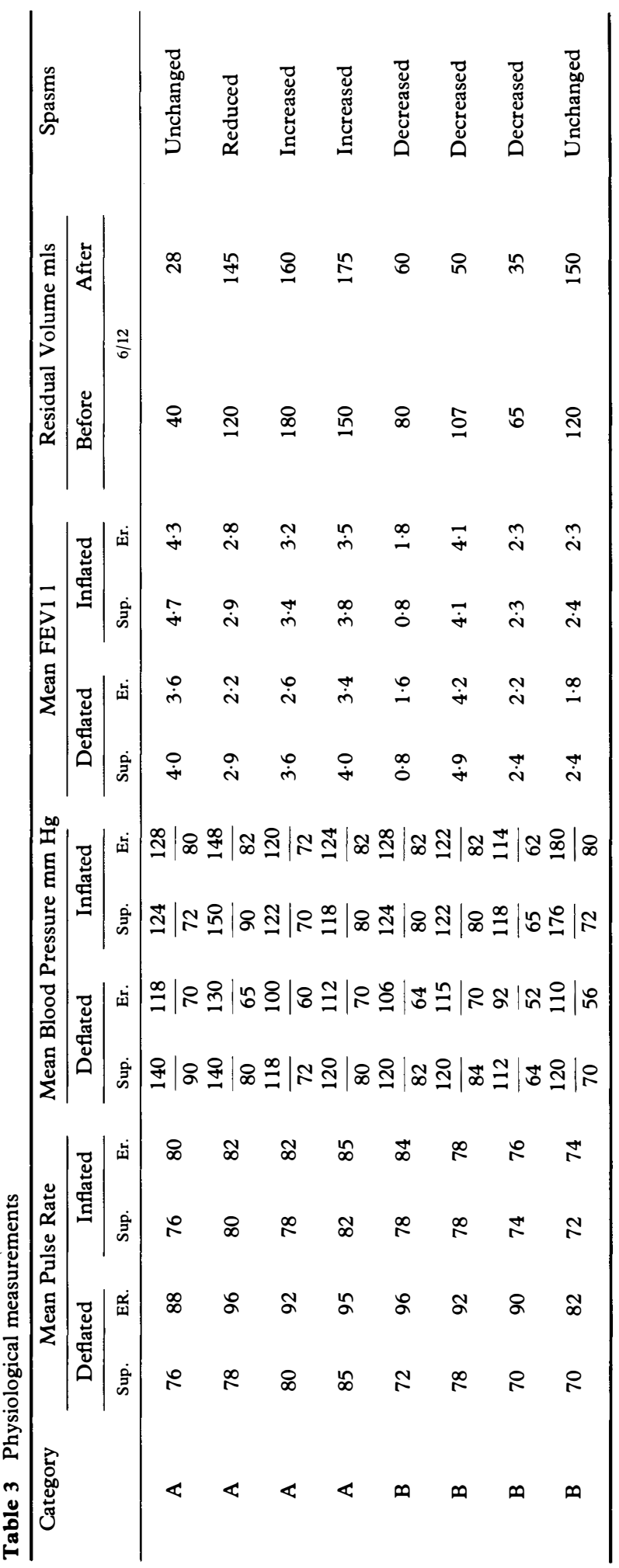


scoliosis also noted sacral erythema. Three patients were difficult to fit, one because of obesity and spasms causing internal rotation of his legs, the second because of spasms and scoliosis and the third because of spasms alone. Donning the suit became more rapid with time, ventilation in the suit was adequate and the urinary leg bags worked well. Unfortunately two orthoses developed air leaks in a connecting tube but this design fault has now been rectified. The average time to complete the mobilisation programme was 23 hours (16-29 range) over a period of approximately four weeks by which time patients could stand, move considerable distances and negotiate slopes, kerbs and stairs. Ambulation distances were surpassed out of hospital however.

Two of the eight patients failed to complete the programme. One was defeated by persistent spasms but is hoping to try again. The other was scoliotic and had difficulties with fitting and balance. Of the six who completed the course a questionnaire found that four use the suit frequently, one quite frequently and one not at all. This last patient, despite being one of the more proficient subjects, openly admitted apathy and depression which emphasises the necessity for continuing motivation. Significantly, three of the frequent users had previously abandoned calipers. It was difficult to quantify home usage of the orthoses but 30 minutes a day for 4 or 5 days a week was the average. Walks outside and housework were the main activities but one patient managed to get down a steep slope to the beach while on holiday and another got married in his suit. Two patients already employed felt that the suit might allow them to change the nature of their employment but to date no such opportunity has arisen.

\section{Physiological assessment}

Table 3 gives the individual patient data using the standing frame. By inflating the suit, rises in pulse rates in the erect position were reduced by a mean of 10 beats per minute and falls in systolic blood pressure were reduced by a mean of $13 \mathrm{~mm} \mathrm{Hg}$, and falls in diastolic blood pressure were reduced by a mean of $15 \mathrm{~mm} \mathrm{Hg}$. These findings were significant $(\mathrm{p}<0.05)$ and indeed no symptoms of postural hypotension were reported with the suit inflated. Also measured while in the standing frame was forced expiratory volume, FEV1, and with the orthosis deflated in the erect position this usually fell as the abdomen was in most cases hypotonic and thoracic kyphosis increased. However with the orthosis inflated, the abdomen was splinted, the thoracic spine well supported enabling accessory muscles to be recruited and expansion improved. As a result the fall in FEV1 was usually improved, although numbers are too small to achieve statistical significance. Two patients had lateral radiographs of the thoracolumbar spine performed which showed that even in an obese subject the thoracic kyphosis only increased 10 degrees instead of 25 degrees and the lumbar lordosis only increased 5 degrees instead of 15 degrees in comparison between the erect deflated position where the hips and knees alone were supported and the erect inflated position. Residual urinary volumes in all three eventual non-users increased and in one user who subsequently underwent bladder neck surgery. In the other users they decreased but this could have been due to other factors such as bladder training. Cystograms were performed and one case of unilateral vesicoureteric reflux was noted when the patient was erect with the orthosis inflated 


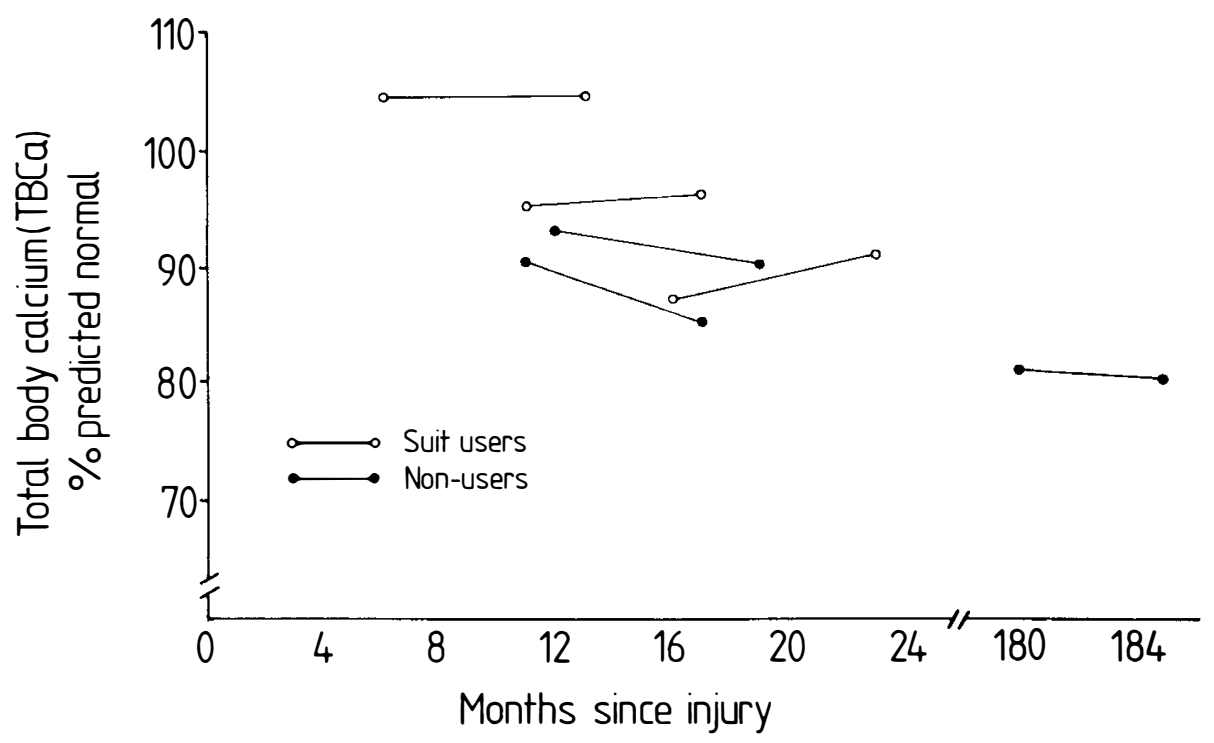

Figure 2. Changes in Total Body Calcium.

but this occurred in the same patient who later underwent bladder neck surgery. The effect on muscle spasms was difficult to quantify but in the five eventual users four reported spasms to be decreased during and for up to an hour after use and one reported no change. The patient who completed the training but failed to use the orthosis at home reported an increase in spasms and needed medications increased. Also, one of the two failed trainees noted a severe increase in spasms on mobilisation.

\section{Haematological and renal function, total body calcium}

Haemoglobin, white cell count and mean corpuscular volume did not change significantly or correlate with mobilisation. Similarly plasma urea, creatinine and creatinine clearance were not significantly improved.

Plasma calcium, phosphate, alkaline phosphatase and parathormone did not correlate with mobilisation although low levels of parathormone were recorded in user and non-user groups. Similarly urinary calcium, phosphate and creatinine estimations did not correlate with mobilisation although no significant hypercalciuria in any patient was detected on a normal diet. However, urinary hydroxyproline levels were significantly higher in the non-user group $(p<0.05)$ which was also reflected in significant differences in the hydroxyproline/creatinine ratio. The total body calcium results, TBCa, expressed as a percentage of predicted normal are shown in Fig. 2. It can be seen that there is an inverse correlation between the TBCa value and the time since injury $(r=-0.95$, $\mathrm{p}<0.05$ ). It can be seen that the three patients who were non-users all lost TBCa whereas the users all gained or remained constant. This gain or loss of users or non-users is significant at $p=0.05$ using Fisher's Exact Test. The increase in TBCa in the users appears to be a function of the initial TBCa. 
The mean rate of loss in the non-users whose time since injury was about one year at time of initial measurement was $0 \cdot 7$ per cent per month. This loss was greater than the non-user whose time since injury was fifteen years and whose TBCa had appeared to plateau at 82 per cent of predicted normal. Interestingly, no changes in weight greater than 1 Kilogram were detected over the six month period which might be due to indoctrination against obesity during the trial period as well as increased physical activity, although unchanged weights were observed in both user and non-user groups. Also total body calcium, prior to mobilisation, appeared to have decreased at a rate of aprroximately 0.8 per cent per month up to 20 months after injury in all but one case of a very athletic individual who maintained a higher than predicted normal total body calcium throughout.

\section{Discussion}

\section{Mobilisation and utilisation}

Rideau et al. (1975) has studied over several years, a mixed population of patients with incomplete and complete spinal cord lesions of varied aetiology. His patients also varied in age, weight, previous mobility and time since injury. Fifty-nine per cent of his patients could be trained to use the orthosis and seventy-seven per cent of these continued to use it at home. The average life span of a suit was 22 months which compares well with conventional orthoses. Silber (1975), had similar results in a study of 11 patients. However, McAdam and Natvig (1980), after a long training programme, managed to mobilise 70 per cent of a mixed group of high and low paraplegics in pelvic brace and calipers, but our experience suggested that calipers were often discarded after discharge from hospital particularly by high lesion paraplegics.

This was also found by Cochlan (1980) who stated that for functional walking it is necessary to have Grade 3 abdominal, back extensor and hip musculature. Mikelberg (1981) has also found low utilisation rates in a questionnaire sent to paraplegics after initial training. Rosman and Spira (1974) showed that individuals at T1-T6 levels did not use orthoses at all and that only a few with T7-T11 lesions used orthoses for standing purposes. Huang et al. (1979) has noted the high energy cost and low ambulation velocity in brace users and Clinkenbeard (1964) found that the rate of ambulation tends to increase as the level of lesion becomes more caudal and that the energy cost per unit of distance tends to decrease as the level of lesion descends. Silber (1975) suggested that ambulation distances of over 200 yards were unexpectedly good but ambulation distances of up to 1000 yards as shown in Table 2 in this series, even in patients who had previously abandoned calipers, confirmed the clinical impression that stability was improved and that effort was reduced. Unfortunately no actual comparison between types of orthosis was made, using for example measurement of oxygen uptake. The weight of the pneumatic orthosis at $4.0 \mathrm{Kg}$ compares favourably with that of pelvic brace and calipers at $7.0 \mathrm{Kg}$. The cost at $£ 500$ to $£ 900$, according to make, also compares favourably with that of a pelvic brace and calipers. 


\section{Physiological assessment}

We agree with Silber (1975) that significant reductions in postural tachycardias and hypotension are achieved, presumably by prevention of venous pooling and recruitment of postural reflexes. Forced expiratory volume is also improved in the erect position by the inflated orthosis by a complex interaction of abdominal splinting, recruitment of accessory muscles of respiration and reduction in the thoracic kyphosis. Silber found that the overall average reduction in vital capacity while erect without the orthosis was $710 \mathrm{cc}$ and only $124 \mathrm{cc}$ with the pneumatic orthosis. Spasms may be reduced in certain cases but increased in others.

\section{Total body calcium}

Pathological fractures in osteoporotic bone in established spinal cord injury can cause problems with internal fixation, pressure sores and contractures, Freehafer et al. (1981). Minaire et al. (1982), has suggested that a steady state of calcium balance may be achieved by 6 months. Hancock (1979), found that using Americium 241 monoenergetic radiation, a parameter related to bone mass could be obtained and suggested that bone loss only occurred less than one year after injury. Our results however suggest that a negative balance may continue up to twenty months after injury and possibly longer. Bergmann (1977), found that in the first two months post injury bone calcium turnover rate is elevated in the non-paralysed area, but after 3 months the reverse is true with a rapid loss infralesionally, maximal between three and ten months. Unfortunately we could not divide our results into upper and lower halves of the body.

In healthy subjects on bed rest, Naftchi found that initial hypercalciuria was less than paralysed patients but also that in paraplegia rehabilitation exercises leading to weight bearing on long bones did not appear to diminish hypercalciuria, although this study was only carried out to 16 weeks post injury. Kaplan et al. (1981), however found that using a tilting table in tetraplegia increases in Total Body Calcium but no reductions in calcium excretion related to successful mobilisation.

Naftchi et al. (1980), found urinary excretion of calcium to be maximal up to 7 weeks after injury but also to find significantly greater loss than controls up to 16 weeks. We also found no late hypercalciuria but did find significant differences in hydroxyproline excretion between orthosis user and non-user groups.

\section{Conclusions}

Paraplegic patients with poor or absent control over the pelvis and thoracolumbar spine benefit from the use of a pneumatic orthosis extending from the midthoracic region to the ankles even when calipers have failed. Certain physiological effects including improvements in cardiovascular function, respiratory function, spasms and total body calcium occur but specific contraindications to prescription of the suit include severe spasms, scoliosis, contractures and obesity which can lead to instability, increased ambulation effort and skin problems. There is no doubt that patients' physical and mental well-being is improved and other areas of rehabilitation benefit from new achievements. To speed up 
the process, orthoses should be available from stock. At home the quality of life in terms of mobility is improved but the general pattern of life and work seem to be unaffected with the wheelchair remaining the basic tool. In some ways, including appearance, the suits are more socially convenient but in others such as inflation difficulties and deflation noises they are not. The latter problem can be masked with ingenuity but as Silber has suggested a joint at the hip might be the solution to inflation problems. Indeed a hybrid pneumatic orthosis with locking hinges at the hip and knee would appear to be a potential solution.

\section{Acknowledgements}

We wish to thank the Prosthetics and Orthotics Committee of the Scottish Home and Health Department for their generous financial assistance. We are indebted to Miss Rosemary Mileham and the other members of the Physiotherapy Department at Edenhall Hospital and of course to the patients whose enthusiasm made this study worthwhile.

\section{Résumé}

Les orthèses pneumatiques ont été utilisées chez huit patients qui, a cause d'un accident, etaient souffrants d'une paraplégie thoracale. Le progrès fonctionel et physiologique fut évalué au cours de deux ans. Quant à la stabilité du bassin et de la colonne vertebrale du dos les orthèses pneumatique sont favorables a des autres armatures orthopédiques. La vigeur cardio-vasculaire et respiratoire est améliorée. Le réservoir total du calcium est augmenté. Spasmes périphériques, obésité et scolioses ne sont pas compatibles avec les orthèses pneumatiques.

\section{Zusammenfassung}

Pneumatische Orthesen wurden bei acht Patienten verwendet, die sich bei Unfällen eine thorakale Paraplegie zugezogen hatten. Die funktionelle und physiologische Fortentwicklung der Patienten wurde über zwei Jahre verfolgt: Die pneumatischen Orthesen stützen das Becken und die dorsolumbale Wirbelsäule besser ab als andere Apparate. Die kardiovaskuläre und respiratorische Leistungsbreite werden verbessert, das Kalziumreservoir vergrössert. Periphere Spastik, Adipositas und Skoliosen sind Kontraindikationen von pneumatischen Orthesen.

\section{References}

Bergmann P, Heilporn A, Schoutens A, Paternot J, Tricot A 1977 Longitudinal study of calcium and bone metabolism in paraplegic patients. Paraplegia 15:147-159.

Clinkingbeard JR, Gersten JW, HoEHN D 1964 Energy cost of ambulation in the traumatic paraplegic. American Journal of Physical Medicine 43:157-165.

Coghlan JK, Robinson CE, Newmarch B, Jackson G 1980 Lower extremity bracing in paraplegia - a follow-up study. Paraplegia 18:25-32.

FREEHAFER AA, HAZEL CM, BECKER CL 1981 Lower extremity fractures in patients with spinal cord injury. Paraplegia 19:367-372.

Hancock DA, Reed GW, Atkinson PJ, Cook JB, Smith PH 1979 Bone and soft tissue changes in paraplegic patients. Paraplegia 17:267-271.

Huang C, Kuhlemeier KV, MoORe NB, Fine PR 1979 Energy cost of ambulation in paraplegic patients using Craig-Scott braces. Archives of Physical Medicine and Rehabilitation 60:595-600.

Kaplan PE, Roden W, Gilbert J, Richards L, Goldschmit JW 1981 Reduction in hypercalciuria in tetraplegia after weight bearing and strengthening exercises. Paraplegia 19:289-293.

Kennedy NSJ, Eastell R, Ferrington CM, Simpson JD, Smith MA, Strong JA, Tothill P 1982 Total body neutron activation analysis of calcium: Calibration and normalisation. Physics in Medicine and Biology 27:697-707. 
Mikelberg R, Reid S 1981 Spinal cord lesions and lower extremity bracing: An overview and follow-up study. Paraplegia 19:379-385.

Minaire P, Meunier P, Edouard C, Berard E, Pilonchery G 1982 Histomorphometric study of acute osteoporosis in paraplegic patients. Paraplegia 20:281.

MOREL G 1971 Un nouveau type d'appareillage orthopaedique, l'appareillage a attelles penumatiques. Revue de Chirargie Orthopedique et Reparatrice de l'Appareil Moteur 57:409-414.

McAdam R, Natvig H 1980 Stair climbing and ability to work for paraplegics with complete lesions-A sixteen year follow-up. Paraplegia 18:197-203.

Naftchi NE, Viau AT, Sell GH, Lowman EW 1980 Mineral metabolism in spinal cord injury. Archives of Physical Medicine and Rehabilitation 61:139-142.

Rideau Y, MORel G, Barrachina L, Benassy J 1975 Premiere analyse critique de l'utilisation des ortheses pneumatiques. Annales de Medecine Physique 18:1-27.

Rosman N, SPIRA E 1974 Paraplegic use of walking braces: a survey. Archives of Physical Medicine and Rehabilitation 55:310-314.

Silber M, Chung TS, Varghese G, Hinterbuchner C, Bailey R, Hivry R 1975 Pneumatic Orthosis: Pilot study. Archives of Physical Medicine and Rehabilitation 56:27-32. 